\title{
Increased knowledge transfer by using modern high-speed camera
}

\section{Dan Curticapean, Peter Wozniak, Kai Israel, Oliver Vauderwange, Paul Dressler}

Dan Curticapean, Peter Wozniak, Kai Israel, Oliver Vauderwange, Paul Dressler, "Increased knowledge transfer by using modern high-speed camera," Proc. SPIE 9188, Optics Education and Outreach III, 91880G (15 September 2014); doi: 10.1117/12.2061875

EDent: SPIE Optical Engineering + Applications, 2014, San Diego, California, United States 


\title{
Increased Knowledge Transfer by Using Modern High-Speed Camera
}

\author{
Dan Curticapean ${ }^{1 *}$, Peter Wozniak ${ }^{1}$, Kai Israel ${ }^{1}$, Oliver Vauderwange ${ }^{1}$, Paul Dreßler ${ }^{1}$ \\ ${ }^{1}$ Offenburg University, Badstr. 24, 77652 Offenburg/Germany
}

\begin{abstract}
A broad theoretical knowledge in Optics and Photonics is essential for media engineers. A combination of theory in the lectures augmented by practical work during the laboratory experiments forms the foundation of our gradual approach in communicating clearly and intensively all of the required topics. All laboratory experiments are guided but carried out by the students themselves and produced with a modern high-speed camera. This offers possibilities to analyze and iterate very fast phenomena. The slow motion footage makes it easily to analyze, to measure and to calculate certain sequences. This leads to a very intensive discussion regarding the provided topics and the used camera technology, resulting in a high standard knowledge transfer. Physics get now visible and more accessible for students.
\end{abstract}

This paper presents how the students execute and analyze experiments using modern technology. The results are prepared as media-friendly computer animation and video recordings.

Keywords: Educations, Education in Optics and Photonics, High-speed Camera

\section{INTRODUCTION}

The first high-speed image probably has been taken in 1851 by Tablot when he achieved to freeze the motion of a fast spinning wheel with a piece of newspaper on it on a photograph [1] - [2]. In his experiment he used a camera with a slow shutter, a darkroom and an arc flash to freeze the motion. The short duration of the flash of approximately $1 / 2000 \mathrm{~s}$ [1] led to a short exposure time, a short light integration time and therefore a tack sharp and still readable photograph of the newspaper. Subsequently High-speed photography led to High-speed cameras, which allowed one to capture more than one picture at once. Compared to the usual 24, 25, 30, 50 or 60 frames per second of consumer camcorders, modern High-Speed cameras allow capturing more than a million frames per second [3]. The playback of such a high-speed photo sequence at a lower frame rate allows a temporally detailed observation of very fast, to the human eye usually invisible, processes and events.

The changeover from the formerly used film and mechanical shutters towards CCD or CMOS sensors and electronic shutters allowed a more precise control of the frame rate and light integration time. The knowledge of the exact light integration period and frame rate allows a wide range of possible applications. Therefore high-speed cameras became an important but expensive tool to study a wide variety of phenomena qualitatively and quantitatively [3] - [4].

Technical advancements in microelectronics and computer technology led to more affordable prices and thus the increased use for educational purposes.

\section{EDUCATIONAL OBJECTIVES}

As for the educational objectives the students have to cope with a set of different tasks to successfully conclude the assignment. First of all they have to learn how to operate a high-speed camera and its operating software. Besides the knowledge of what can be measured, it is also essential to understand how these measurements can be gained and what measurement setup perquisites are crucial. Afterward the students have to interpret and discuss their results and any derivations from what they would have expected.

\footnotetext{
dan.curticapean@hs-offenburg.de
} 


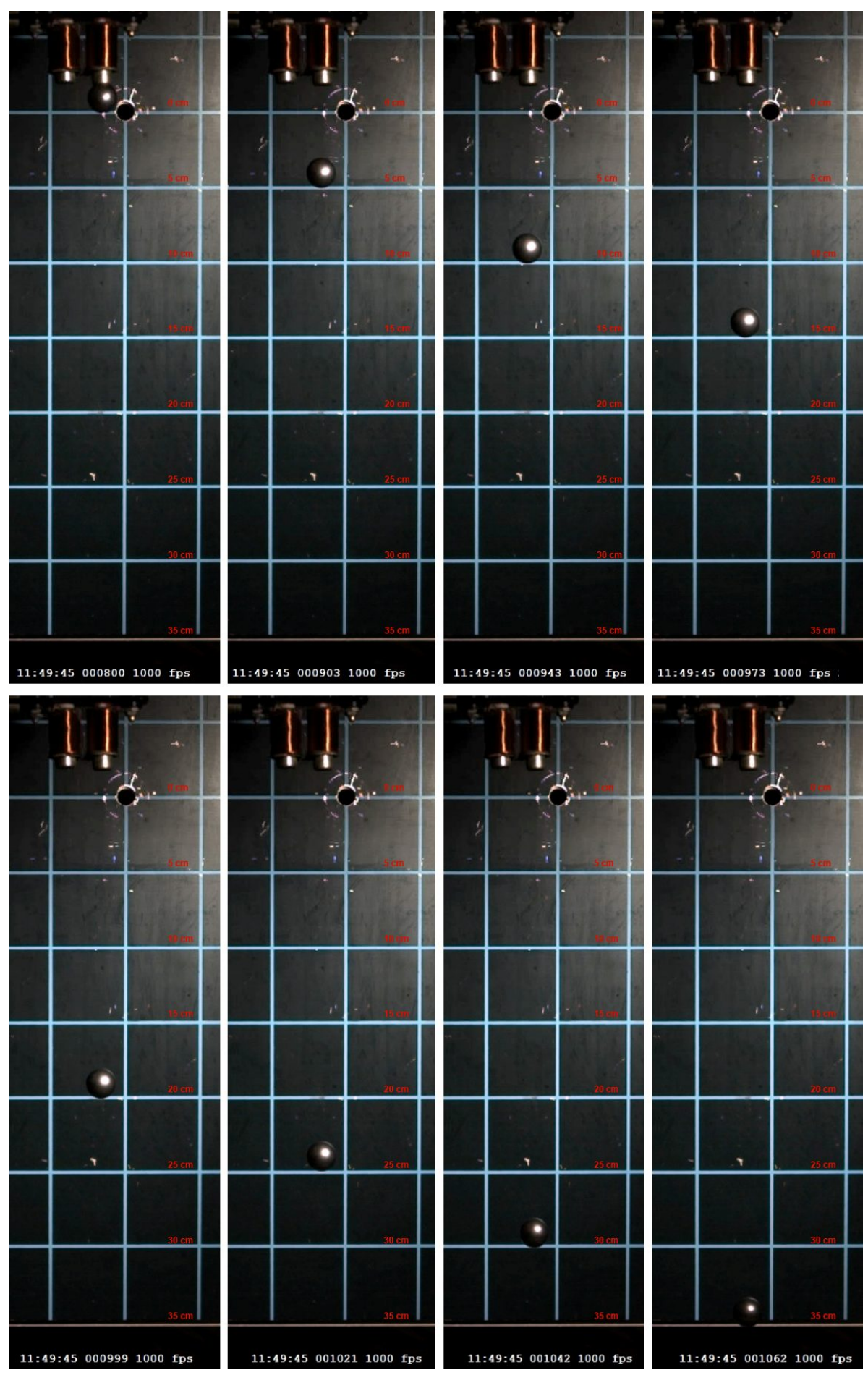

Figure 1 High-speed recording of a metal sphere in free fall experiment to measure the gravity acceleration Video 1 http://dx.doi.org/10.1117/12.2061875.1

Proc. of SPIE Vol. 9188 91880G-2 


\section{EXPERIMENTAL MEASUREMENTS FOR THE FREE FALL}

In one of our experiments we show our students how to derive gravity acceleration from a filmed drop test. In this simple experiment a metal sphere is released from its magnetic holding coil and falls in front of a metric scale towards the floor. The high-speed recording enables the students to observe the accelerated movement of the ball within the recordings period and its single frame intervals (Figure 1). The exact knowledge of each individual frame time duration and the observed travelled distance of the ball allows them to calculate the applied acceleration and thus the gravity acceleration $[5]-[14]$

$$
h=h_{0}+v_{0} t+\frac{g t^{2}}{2}
$$

It is very important to align the coordinate system reference to the spheres initial resting position. By doing so we define appropriate initial conditions of zero initial velocity $\left(\mathrm{v}_{0}=0 \frac{\mathrm{m}}{\mathrm{s}}\right)$ and zero initial height $\left(\mathrm{h}_{0}=0 \mathrm{~m}\right)$. These simplifications allow us to rewrite the equation (1) to calculate the gravity acceleration $\mathbf{g}$ as shown in (2)

$$
g=\frac{2 h}{t^{2}}
$$

Like mentioned before to use equation (2) the spheres initial velocity and height must be zero. The knowledge of the used frame rate allows calculating the past time for every distinct frame. As seen in fig. 1 we defined frame 800 as our initial starting point, thus all following frames can be used to calculate the past time and measure the travelled distance.

\begin{tabular}{|c|c|c|c|c|c|c|c|c|c|}
\hline $\mathrm{h}$ & Frame & $\begin{array}{c}\text { Frame } \\
\text { Difference }\end{array}$ & Time & $\mathrm{g}_{\mathrm{i}}$ & $\overline{\mathrm{g}}$ & $\mathrm{g}_{\mathrm{i}}-\overline{\mathrm{g}}$ & $\left(\mathrm{g}_{\mathrm{i}}-\overline{\mathrm{g}}\right)^{2}$ & $\sigma$ & $\Delta$ \\
\hline $\mathrm{cm}$ & & & $\mathrm{s}$ & $\frac{\mathrm{m}}{\mathrm{s}^{2}}$ & $\frac{\mathrm{m}}{\mathrm{s}^{2}}$ & $\frac{\mathrm{m}}{\mathrm{s}^{2}}$ & $\left(\frac{\mathrm{m}}{\mathrm{s}^{2}}\right)^{2}$ & $\frac{\mathrm{m}}{\mathrm{s}^{2}}$ & $\frac{\mathrm{m}}{\mathrm{s}^{2}}$ \\
\hline 0 & 800 & 0 & 0,000 & & & $-0,565$ & 0,319 & \\
5 & 903 & 103 & 0,103 & 9,426 & & $-0,210$ & 0,044 & \\
10 & 943 & 143 & 0,143 & 9,780 & & $-0,082$ & 0,007 & \\
15 & 974 & 174 & 0,174 & 9,909 & & 0,110 & 0,012 & $\mathbf{0 , 3 0 8}$ \\
20 & 999 & 199 & 0,199 & 10,101 & $\mathbf{9 , 9 9 1}$ & $\mathbf{0 , 1 1 6}$ \\
25 & 1021 & 221 & 0,221 & 10,237 & & 0,247 & 0,061 & \\
30 & 2042 & 242 & 0,242 & 10,245 & & 0,254 & 0,065 & \\
35 & 1061,5 & 261,5 & 0,2615 & 10,237 & & 0,246 & 0,060 & \\
\end{tabular}

Table 1 shows the calculation of $g$ and the error of $g$

Table 1 presents the resulting measurement and corresponding calculation of $g$ by using (2). The students furthermore have the task to determine $\mathrm{g}$, the measurement errors

$$
\mathrm{g}=9,99 \frac{\mathrm{m}}{\mathrm{s}^{2}} \pm 0,12 \frac{\mathrm{m}}{\mathrm{s}^{2}}
$$

and conclude by discussing their results.

For our latitude the theoretical value for $\mathrm{g}$ is $9,81 \mathrm{~m} / \mathrm{s}^{2}$. However our measurement has a deviation of $0,18 \mathrm{~m} / \mathrm{s}^{2}, \mathrm{which}$ is greater than our calculated error of $0,12 \mathrm{~m} / \mathrm{s}^{2}$. 
In a closer examination of our individual gravity acceleration measurements we notice, that the value for $10 \mathrm{~cm}$ turns out to be the closest to the theoretical value. Especially for small heights the resulting error is usually higher, as it is not easy to determine the exact frame of the ball releasing point. Paradoxically our measurements seem to be closer to the theoretical value for the first half of the travelled distance, while deviating further away with increasing height. The explanation must be justified by the increasing velocity of the falling ball and the decreasing time accuracy due to the limit of the chosen frame rate of 1000 frames per second (fps). The corresponding quantization of the time measurement and thus the accuracy was $1 / 1000$ frames $/ \mathrm{s}=1 \mathrm{~ms}$. To improve the measurements results significantly, the frame rate must be increased. A frame rate of $5000 \mathrm{fps}$ allows for a quantization of time at $200 \mu$ s intervals and thus a considerable increased measurement, especially for greater heights.

\section{EXPERIMENTAL MEASUREMENT (CONSERVATION OF MOMENTUM)}

It is also possible to visualize the laws of conservation of momentum, e.g. an elastic impact of two metal spheres (Figure 2)

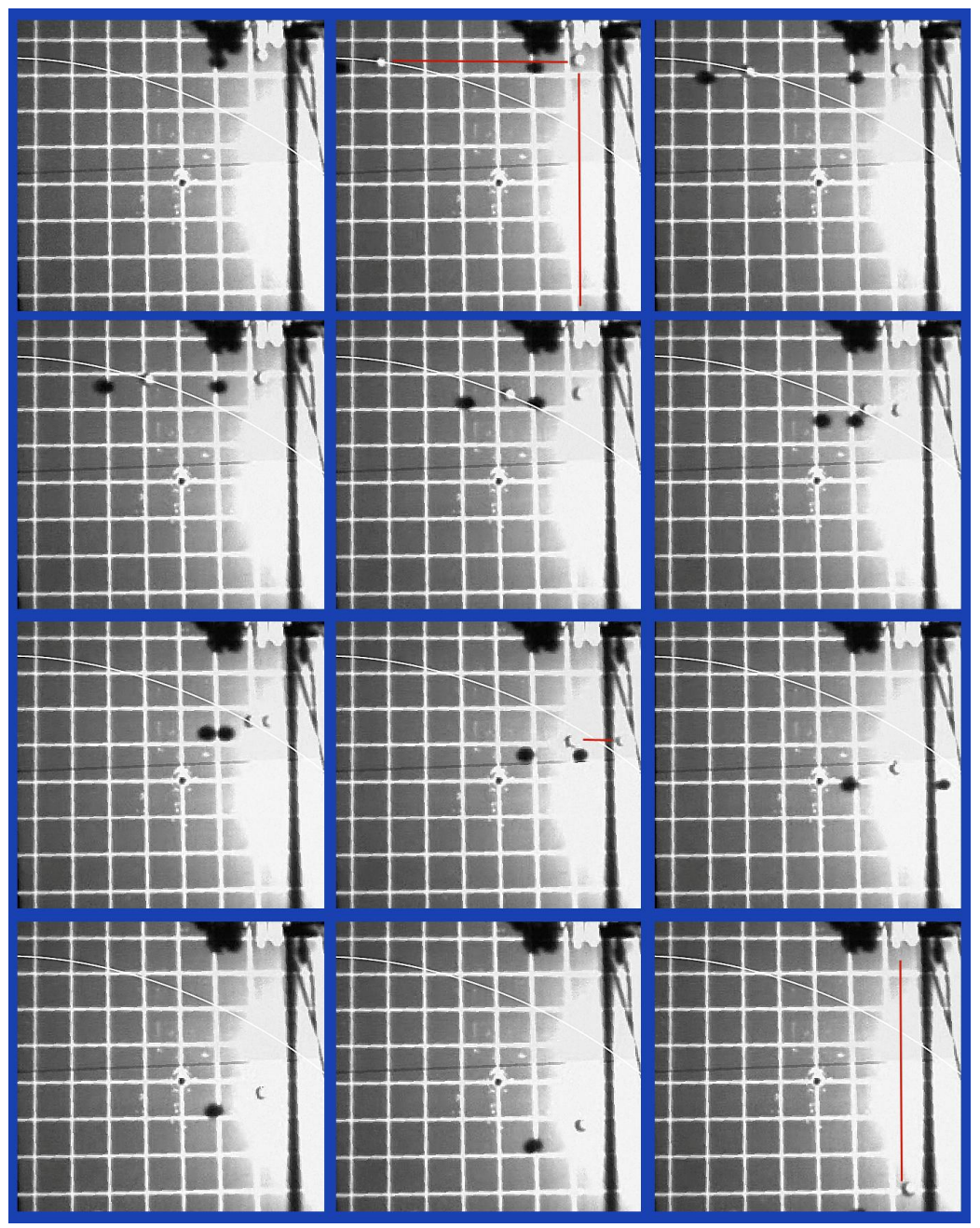

Figure 2 Elastic impact of two metal spheres.

(๔ J. Kässinger, Fl. Lutz, D. Mollenkopf - Offenburg University [15]) 


\section{INTERDISCIPLINARY PERSPECTIVES}

Often enough a collaboration of students from various fields of study is very creative and interesting. Physical effects like e.g. the formation of water drops, the behaviour of water surface tension or even the conservation of momentum can be used for artwork. Figure 3 shows a high-speed image sequence of water drops and the behaviour of water surface tension filmed at 1500 frames per second for the use in a movie.

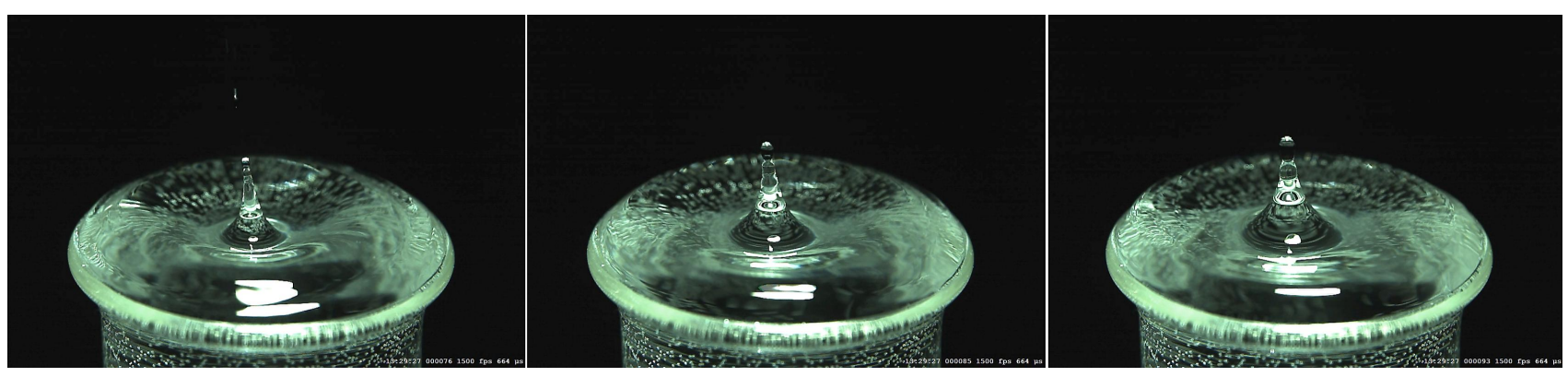

Figure 3 Surface tension behavior of water or simply falling water drops on water surface recorded by 1500 fps. Between the first (Frame 76) and the second picture (Frame 85) are $5976 \mu$ s and between the second and the last picture (Frame 93) are 5312 $\mu$ s. (C D. Curticapean - Offenburg University)

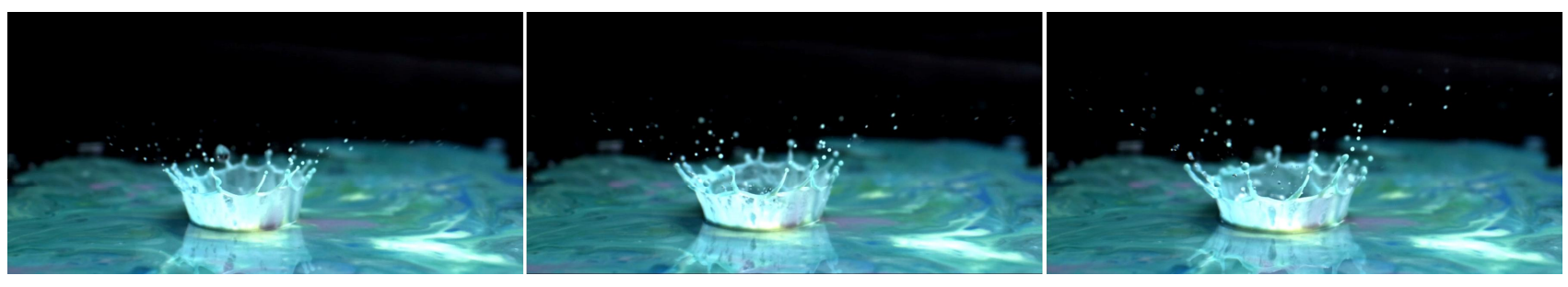

Figure 4 High-speed images of a water drop impact. (C L. Schwabe, B. Bischler, Fr. Cholewa - Offenburg University)

\section{VISUALISING PHYSICS}

As an outlook our next challenge is to solve more complex physical phenomena using a high speed camera.

Consider the system from the Figure 5. A body with the mass m moves along a sphere with the radius $\mathrm{R}$. The angle $\varphi$ at which the small body lifts off of the sphere is to be determined and can be calculated analytically as follows: 


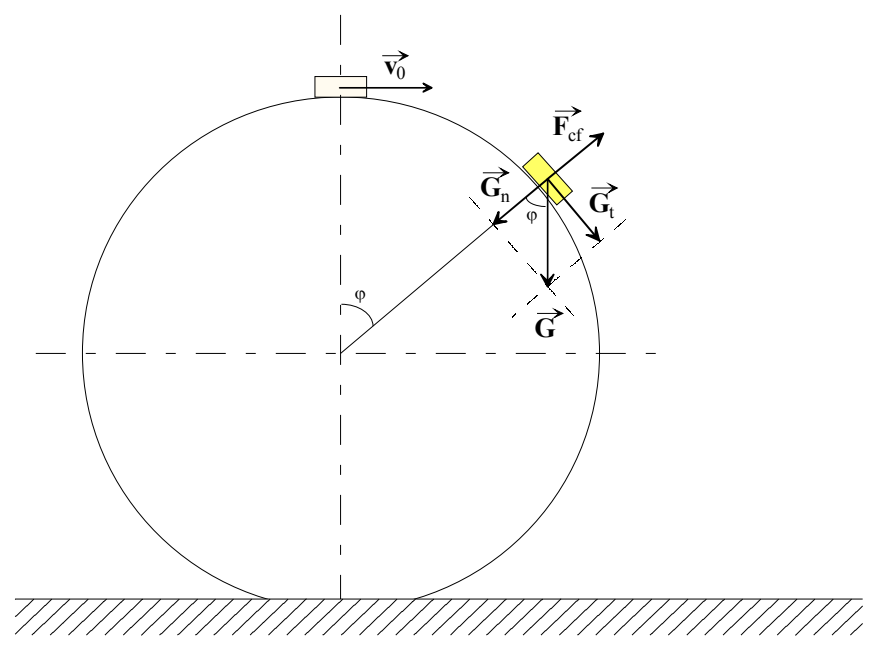

Figure 5: Schematic set-up of the experiment

The body of mass $m$ lifts of the surface of a sphere in the moment when condition (4) is fulfilled (the centrifugal force compensates the radial force):

$$
\frac{\mathrm{mv}}{\mathrm{R}}=\mathrm{mg} \cos (\varphi)
$$

The speed at this moment results considering the law of conservation of energy:

$$
\mathrm{mgR}+\frac{\mathrm{mv}_{0}^{2}}{2}=\operatorname{mgR} \cos (\varphi)+\frac{\mathrm{mv}^{2}}{2} .
$$

As a conclusion the angle where the body lifts of from the spheres surface results:

$$
\varphi=\arccos \left(\frac{2}{3}+\frac{\mathrm{v}_{0}^{2}}{3 \mathrm{gR}}\right) .
$$

The speed limit at which the angle is zero

$$
\varphi=0^{\circ} \quad \Rightarrow \quad \cos (0)=1
$$

results from the equation (6):

$$
1=\frac{2}{3}+\frac{\mathrm{v}_{0}^{2}}{3 \mathrm{gR}}
$$

thus $\mathrm{v}_{0}$ is

$$
\Rightarrow \quad \mathrm{v}_{0} \geq \sqrt{\mathrm{gR}}
$$

The concluding result is not surprising. 
By using a high-speed camera we can examine the frames for the calculated angle $\varphi$ (Figure 6). Even though the frame shows the system for the correct angle, we can't determine for sure if the objects body has lifted off the spheres body. On the one hand the objects mass $m$ is not small enough and isn't sliding ideally along the tangent arc, which is located perpendicular to the lenses cone of view. Thus the precise moment of the body's lift off is not exactly determinable. To solve these issues a special mechanism needs to be developed and will be the topic of a further publication. And on the other hand we neglected friction forces.

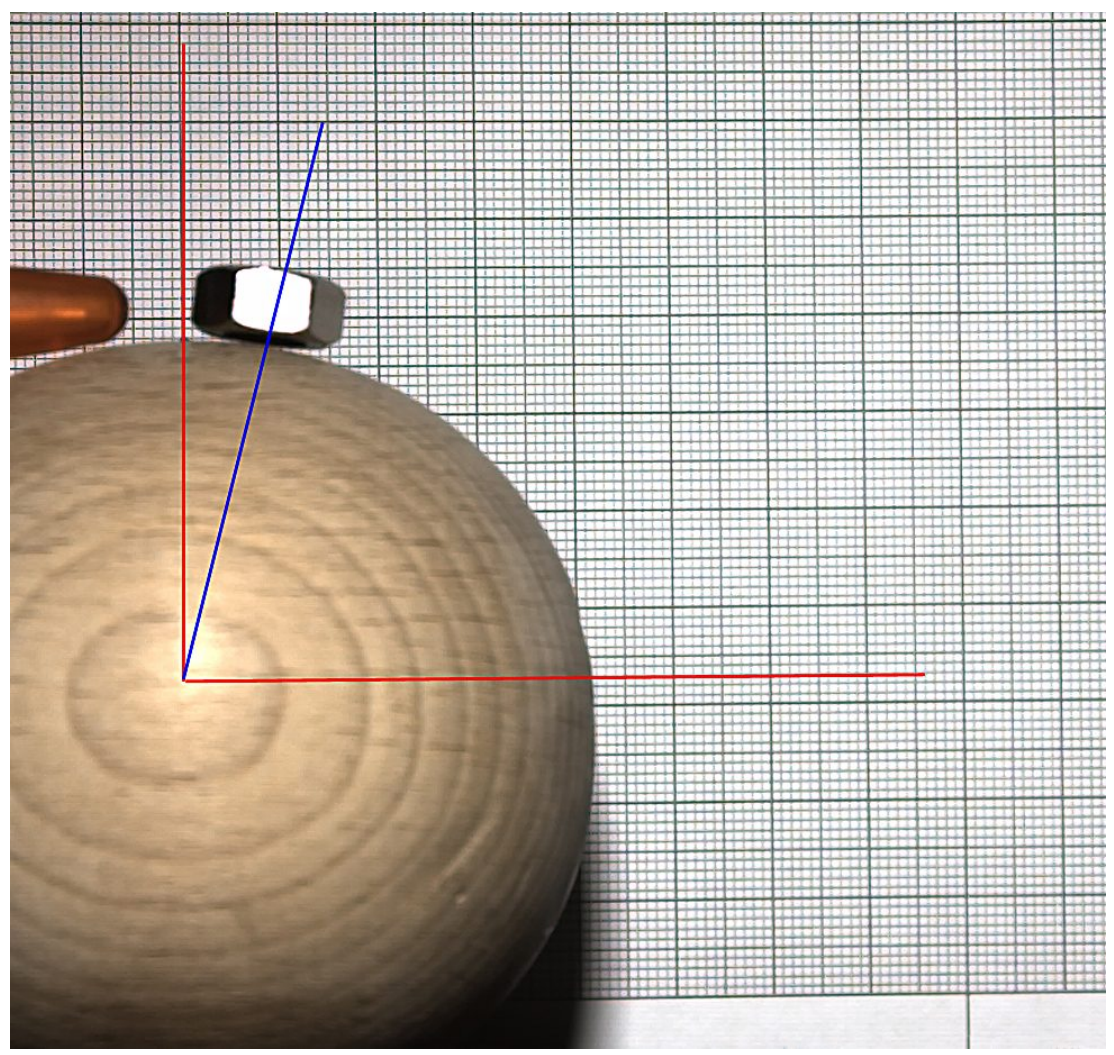

Figure 6: High-speed FRAME of the process (3215fps)

\section{REFERENCES:}

[1] Vollmer, M., Möllmann, K., "High speed and slow motion: the technology of modern high speed cameras", Phys. Educ., 46(2) , 192-202, (2011)

[2] Ang, T., [Photographie], Dorling Kindersley Limited, London (2005)

[3] Larry Hardesty, "trillion fps camera", 13.12.2011, http://newsoffice.mit.edu/2011/trillion-fps-camera-1213 $(03.07 .2014)$

[4] ***, "billion fps camera" 03.07.2014, http://specialised-imaging.com/products/simx-ultra-high-speed-framingcamera (03.07.2014)

[5] Tipler, P. A. and Llewellyn. R. A., [Moderne Physik], Oldenbourg Verlag, München, (2010)

[6] Tipler, P. A. and Mosca, G., [Physisk für Wissenschaftler und Ingenierue], Spektrum Akademischer Verlag, Heidelberg, (2009) 
[7] Knight, R. D. [Physics for Scientists and Engineers a strategic approach second edition], Pearson AddisonWesley, San-Francisco, (2008)

[8] Orear, J., [Physik], Carl Hanser Verlag, München \& Wien, (1982)

[9] Radi, H. A., [Principles of Physics for Scientists and Engineers], Springer-Verlag, Berlin \& Heidelberg, (2013)

[10] Paus, H. J., [Physik in Experimenten und Beispielen], Carls Hanser Verlag, München, (2007)

[11] Alonso, M. and Finn, E. J., [Physik], Addison-Wesley, Bonn \& München, (1988)

[12] Feynman, R. and Sands, M., [Feynman Vorlesungen über Physik], Oldebourg Verlag, München \& Wien, (2007)

[13] Povh, B. and Soergel E., [Anschauliche Physik : für Naturwissenschaftler], Springer Spektrum, Berlin \& Heidelberg, 17-19 (2014).

[14] Hewitt. P. G. and Suchocki, J. and Hewitt, L. A. [Conceptual Physical Science Third Edition], Pearson Education, San Francisco, (2004)

[15] Kässinger, J., Lutz, Fl., Mollenkopf, D., [Hochgeschwindigkeitsaufnahmen], Offenburg University, (2010). 